\title{
Synergistic Separation of Rare Earth Elements (REEs, La-Lu), Y and Th From U-, Nb-, and Ta-Rich Refractory Minerals for Determination by ICP-AES
}

\author{
M. Krishnakumar ${ }^{a}$, K. Satyanarayana ${ }^{b}$, and K. Mukkantic \\ a Chemistry Group, Atomic Minerals Directorate for Exploration and Research, \\ Department of Atomic Energy, Begumpet, Hyderabad-500016, India \\ ${ }^{b}$ Rajiv Gandhi University of Knowledge Technologies, I.I.I.T-Basara, Adilabad District, A.P-504107, India \\ c Institute of Science and Technology, Jawaharlal Nehru Technological University-Hyderabad, \\ Kukatpally, Hyderabad-500085, India
}

\begin{abstract}
The determination of rare earth elements (REEs, La-Lu), $\mathrm{Y}$ and Th in uranium-, niobium-, and tantalum-rich refractory mineral samples by inductively coupled plasma atomic emission spectrometer (ICP-AES) is challenging due to spectral and matrix interferences. In this paper, a simple, rapid, and accurate method for the synergistic and selective separation of REEs, $\mathrm{Y}$, and $\mathrm{Th}$ as their oxalates from the fused potassium bisulphate leachates of refractory minerals rich in $\mathrm{U}, \mathrm{Nb}$, and $\mathrm{Ta}$ is described. The oxalates of the analyte elements are precipitated, whereas that of the matrix elements remained in the solution achieving a near complete separation.
\end{abstract}

A synergism during the precipitation of the analyte oxalate and sulphate was observed for the complete recovery of the analytes. The method was validated by preparing and analyzing a synthetic mixture similar to a samarskite and quantitative recoveries were obtained. The same method was applied to a certified reference material of columbite (IGS-33) and a few geological samples. The values were compared with the results obtained by other established/ reported methods of separation and determination of analytes in similar matrices. The method was highly reproducible with an RSD of $1-3 \%$ at the concentration of the analytes present in samarskite- $/$ fergusonite-/euxenite-type of matrices.

\section{INTRODUCTION}

Rare earth elements (REEs) and their compounds are in high demand and often crucial for a broad and rapidly expanding range of applications that relies on their chemical, catalytic, electrical, magnetic, and optical properties (1). They are a coherent group of elements that show very similar chemistry and in no case are found in isolation. However, certain elements of this group are found in abundance in a particular mineral such as the lighter REEs, or $\mathrm{La}, \mathrm{Ce}, \mathrm{Pr}$, and $\mathrm{Nd}$ in monazite or $\mathrm{Y}$ in xenotime. Nio-

\footnotetext{
*Corresponding author. :E-mail: kkatdae@gmail.com or krishnakumar.amd@gov.in
}

bium and tantalum are used for manufacturing corrosion-resistant nuclear reactor materials such as fuel bundle cladding materials, reactor vessels, and other related components (2). They are also used in semiconductors and superconductors in the electronics industry. In these materials, even the presence of trace impurities has a critical effect on the properties of the electronics products. In nuclear materials, separation and individual determination of these elements with concomitants such as REEs, $\mathrm{Y}$, and Th is very important in hydro-metallurgical quality control since some of these elements (Ce, Sm, Eu, Gd, Dy, and Er) are strong neutron absorbers. For sustainable production of nuclear energy, the availability of the strategic metals $\mathrm{Nb}, \mathrm{Ta}, \mathrm{Zr}$, Ti, etc., should be plentiful. Pegmatites are the major sources of the minerals of $\mathrm{Nb}, \mathrm{Ta}$, REEs, Y, and Sc such as niobate, tantalite, samarskite, fergusonite, euxenite, and carbonatite. During the exploration for valuable metals like $\mathrm{U}, \mathrm{Th}, \mathrm{Nb}, \mathrm{Ta}, \mathrm{Be}, \mathrm{B}, \mathrm{Li}, \mathrm{Zr}$, and rare earths, it is highly probable for analytical geochemistry laboratories to analyze rock and mineral samples having complex matrices.

For chemical characterization of materials by inductively coupled plasma atomic emission spectrometer (ICP-AES), preparation of a homogeneous solution with minimum dissolved salts content is desirable. The dissolution of mineral samples containing elements with high ionic potential, $\mathrm{Nb}, \mathrm{Ta}$, $\mathrm{Ti}, \mathrm{Zr}$, etc., is challenging owing to the fact that they are readily hydrolyzed in aqueous solutions and form niobium and tantalum oxy-oxides. Thus, the routine application of mineral acids does not disintegrate these refractory samples effectively. For this reason, the analyst resorts to fusion with a flux and dissolution of the cooled melt in citric acid or tartaric acid increases the dissolved solids in the solution. This process makes it unfit for introduction into nebulizers of an ICP-AES and ICP mass spectrometer (ICP-MS) for the determination of REEs and other elements. ICP-AES is a multielemental analytical technique for trace and ultra-trace determination of many analytes including s, p, d and $f$ block elements. High sample throughput, large linear dynamic 
range, and absence of chemical interferences are a few of the advantages of the technique. However, the technique is not free from spectral and matrix interferences which in turn deteriorate the detection limit and increase the chances of producing erroneous results.

Therefore, separation of these analytes from the solutions of the interfering matrix elements becomes mandatory before REE determination by ICP-AES. A number of separation methods such as precipitation, co-precipitation (3), solvent extraction of analytes with phosphoric acid esters (4) or extraction of the matrix itself (5), solid phase extraction of analyte fluorides on activated charcoal (6-7) are reported for the separation of REEs, Y, and Th from interfering matrix elements. The commonly used methods of separation for REEs are precipitation of hydroxide, fluoride, and oxalate. Hydroxide precipitation is the least selective. Fluoride precipitation is particularly useful for the collection of trace amounts of rare earths. Oxalate precipitation is the most nearly specific method and separates REEs, Y, Th, and a few alkaline earths from all other matrix elements. An alternate method of separation of the major matrix in Nb-Ta-rich materials would be acid hydrolysis precipitation of $\mathrm{Nb}$ and Ta as their oxychlorides (8). However, during this process uranium remains soluble and an additional separation step needs to be introduced before the determination of REEs by ICP-AES if the uranium concentration is greater than $10 \mu \mathrm{g} / \mathrm{mL}$ in the final solution.

The method proposed employs a simple and rapid potassium hydrogen sulphate KHSO $_{4}$ ) fusion and a synergistic single-step quantitative oxalate double sulphate precipitative separation of the analytes removing the interfering $\mathrm{U}$, hydrolysable elements like $\mathrm{Nb}$ and $\mathrm{Ta}$, which form completely soluble oxalates at $\mathrm{pH} \sim 2$ or less. Quantitative separation of these elements could be achieved and their residual presence $(<10 \mu \mathrm{g} / \mathrm{mL})$ found in the solution did not cause any significant change in measuring the emission intensity of the analytes. Moreover, the solution was clear and stable and the total salts content was also very low. This was established by applying the suggested procedure to a synthetically prepared samarskite matrix. The advantage of synergistic separation of rare earth oxalates in the presence of $\mathrm{KHSO}_{4}$ is also being established and discussed. Hence, the method was applied to a few mineral samples and the results compared well with those values obtained by other established methods. An international certified reference material (CRM) IGS-33, a niobium-rich material (obtained from the Institute of Geological Sciences, U.K.) was also analyzed applying the said procedure. The values obtained were in good agreement with the reported certified results.

\section{EXPERIMENTAL}

\section{Instrumentation}

All emission intensity measurements were made using the radial viewing ICP-AES Model Ultima2 (Horiba Jobin Yvon, France) equipped with a crystal-controlled RF generator of $40.68 \mathrm{MHz}$ and a monochromator (focal length $1 \mathrm{~m}$ ) employing ruled-back-to-back grating of 4320 and 2400 grooves/mm. The sample introduction system had a concentric glass nebulizer and cyclonic spray chamber incorporated with a sheath gas device. Argon gas was humidified before its introduction to the spray chamber. Background corrections were applied wherever necessary. The plasma power was uniformly kept at $1000 \mathrm{~W}$ throughout the experiments. All pH adjustments were made using a digital $\mathrm{pH}$ meter fitted

\section{Atomic}

with a combination glass electrode having automatic temperature control facility (Systronics, India).

\section{Instrument Calibration}

The ICP-AES was calibrated with two methods carefully developed, keeping the sensitivities and interelement interferences in purview. Method-I included a four-point calibration for La, Ce, Gd, Dy, and Nd $(0,0.5,2.0$, and $5.0 \mathrm{ppm})$ and $\mathrm{Th}$, $\mathrm{Y}, \mathrm{Eu}, \mathrm{Yb}$, and $\mathrm{Lu}(0,0.1,0.5$, and $1.0 \mathrm{ppm})$. Method-II had Pr, Tm, $\mathrm{Tb}, \mathrm{Sm}, \mathrm{Ho}$, and $\mathrm{Er}(0,0.5,1.0$, and $2.0 \mathrm{ppm})$. Integration time used was 0.5 seconds and 11 points were used for measurement and 9 points for calculation.

\section{Reagents and Standard Solutions}

The reagents used for preparation of the samples and standards were of analytical reagent grade. All single-element REEs and Y (as oxides) in $1 \mathrm{mg} / \mathrm{mL}$ standard stock solutions were made by dissolving the SpecPure ${ }^{\circledR}$ rare earth oxides (Johnson \& Matthey, UK) in nitric acid, except $\mathrm{CeO}_{2}$ (dissolved in a mixture of $\mathrm{HNO}_{3}$ and $\mathrm{H}_{2} \mathrm{O}_{2}$ ). The stock solution $(1 \mathrm{mg} / \mathrm{mL})$ of Th was prepared from thorium nitrate (Alfa Aesar, Johnson Matthey, UK). Multielement calibration standard solutions were prepared by dilution of the stock solution with Milli-Q ${ }^{\circledR}$ water keeping the final acidity as $3 \%$ (v/v) $\mathrm{HNO}_{3}$.

\section{Procedure}

A $0.200 \mathrm{~g}$ amount of sample was fused in a platinum crucible with about $4 \mathrm{~g}$ of anhydrous $\mathrm{KHSO}_{4}$ until the resulting melt becomes clear. The crucible was cooled and transferred to a beaker containing $4 \%$ (w/v) oxalic acid solution. The contents were heated on a water bath for complete precipitation. The content was cooled and filtered (Whatman No. 542 filter paper), washed five times with $20 \mathrm{~mL}$ each of $1 \%(\mathrm{w} / \mathrm{v})$ oxalic acid solution. 
The filter paper was transferred to a platinum dish, dried and ignited at $650{ }^{\circ} \mathrm{C}$ in a muffle furnace for one hour. The ash was treated with $6 \mathrm{~mL}(1: 1) \mathrm{HCl}$ on a water bath to get a clear solution. After suitable dilution, ICP-AES analysis was carried out using the emission lines as listed in Table I.

\section{RESULTS AND DISCUSSION}

It is understood that more than 150 minerals of REEs exist in the earth (9). Minerals with large cation sites, such as zircon, garnet, apatite, samarskite, fergusonite, etc., readily accept many REE ions such that they can become the minor component of their composition. They occur in association with columbite, zircon, monazite, uraninite, aeschynite, magnetite, albite, topaz, beryl, garnet, muscovite, and biotite (9). Thus, during the analysis of rock samples from the pegmatitic belts it is highly probable to encounter samples with very high concentrations of $\mathrm{U}, \mathrm{Nb}, \mathrm{Ta}$, REEs, and Y.

TABLE I

Wavelengths Used in ICP-AES and Contribution of $U(1 \mathrm{mg} / \mathrm{mL})$ and Improvement in DL After Separation

\begin{tabular}{|c|c|c|c|c|c|c|c|}
\hline \multirow[t]{2}{*}{ Elements } & \multirow{2}{*}{$\begin{array}{l}\text { ICP-AES } \\
\text { Wavelengths } \\
\quad(\mathrm{nm})\end{array}$} & \multirow{2}{*}{$\begin{array}{c}\text { Contribution } \\
(\mu \mathrm{g} / \mathrm{mL}) \\
\text { from } 1 \mathrm{mg} / \mathrm{mL} \\
\mathrm{U}_{3} \mathrm{O}_{8}\end{array}$} & \multicolumn{2}{|c|}{ Before Separation } & \multicolumn{2}{|c|}{ After Separation } & \multirow{2}{*}{$\begin{array}{c}(\%) \\
\text { Improvement } \\
\text { in } \mathrm{DL}^{\mathrm{c}}\end{array}$} \\
\hline & & & $\begin{array}{c}\mathrm{BEC}^{\mathrm{a}} \\
(\mu \mathrm{g} / \mathrm{mL})\end{array}$ & $\begin{array}{c}\mathrm{DL}^{\mathrm{b}} \\
(\mu \mathrm{g} / \mathrm{mL})\end{array}$ & $\begin{array}{c}\mathrm{BEC}^{\mathrm{a}} \\
(\mu \mathrm{g} / \mathrm{mL})\end{array}$ & $\begin{array}{c}\mathrm{DL}^{\mathrm{b}} \\
(\mu \mathrm{g} / \mathrm{mL})\end{array}$ & \\
\hline $\mathrm{La}$ & 333.749 & $(-) 0.19$ & 0.03389 & 0.00102 & 0.03247 & 0.00097 & 4.20 \\
\hline $\mathrm{Ce}$ & 418.660 & $(-) 0.27$ & 0.13183 & 0.00395 & 0.12157 & 0.00365 & 7.78 \\
\hline $\operatorname{Pr}$ & 422.293 & 4.75 & 0.37877 & 0.01136 & 0.37127 & 0.01114 & 1.98 \\
\hline $\mathrm{Nd}$ & 430.357 & - & 0.10923 & 0.00328 & 0.09337 & 0.00280 & 14.52 \\
\hline $\mathrm{Sm}$ & 442.434 & 0.10 & 0.04836 & 0.00145 & 0.04271 & 0.00128 & 11.69 \\
\hline $\mathrm{Eu}$ & 381.965 & $(-) 0.09$ & 0.02058 & 0.00062 & 0.02039 & 0.00061 & 0.92 \\
\hline Gd & 364.620 & $(-) 0.35$ & 0.03156 & 0.00095 & 0.02861 & 0.00086 & 9.36 \\
\hline $\mathrm{Tb}$ & 350.917 & 2.49 & 0.07266 & 0.00218 & 0.07101 & 0.00213 & 2.18 \\
\hline Dy & 353.170 & 0.05 & 0.01705 & 0.00051 & 0.01618 & 0.00049 & 5.11 \\
\hline Ho & 345.600 & $(-) 0.03$ & 0.04968 & 0.00149 & 0.04770 & 0.00143 & 4.00 \\
\hline $\mathrm{Er}$ & 349.910 & 1.96 & 0.02908 & 0.00087 & 0.02804 & 0.00084 & 3.56 \\
\hline $\mathrm{Tm}$ & 346.221 & 0.60 & 0.01893 & 0.00057 & 0.01761 & 0.00053 & 6.95 \\
\hline $\mathrm{Yb}$ & 328.937 & - & 0.01016 & 0.00030 & 0.00947 & 0.00028 & 6.84 \\
\hline $\mathrm{Lu}$ & 261.542 & 0.01 & 0.01286 & 0.00039 & 0.01248 & 0.00037 & 2.96 \\
\hline $\mathrm{Y}$ & 371.029 & 0.03 & 0.01000 & 0.00030 & 0.00953 & 0.00029 & 4.65 \\
\hline Th & 401.913 & 0.10 & 0.08168 & 0.00245 & 0.07518 & 0.00226 & 7.95 \\
\hline
\end{tabular}

${ }^{\mathrm{a}} \mathrm{BEC}=\underline{\text { Concentration }(\mu \mathrm{g} / \mathrm{mL}) \times \text { Background intensity }}$

${ }^{\mathrm{b}}$ Detection limit $(\mathrm{DL})=$ BEC $\times 0.03$ (Peak Intensity-Background Intensity)

${ }^{\mathrm{c}}$ Enhancement in DL\% $=($ DL before separation - DL after separation $) \times 100$ 
Sample dissolution is an integral part of a conventional or instrumental geochemical analysis which ensures the ultimate homogeneity to the sample solution analyzed. A single dissolution method is not universal when the sample analyzed is refractory and complex in nature. Hydrolyzable elements such as $\mathrm{Ti}$, $\mathrm{Sn}, \mathrm{Nb}$, and Ta make it even more difficult when the sample is digested with mineral acids such as $\mathrm{HCl}$ and $\mathrm{HNO}_{3}$ which are the preferred media for introduction to an ICP-AES/ICP-MS. $\mathrm{Nb}(\mathrm{V})$ and $\mathrm{Ta}(\mathrm{V})$, being ions with large ionic potential, attract species which are electron-rich, such as water molecules. On hydrolysis, the corresponding insoluble hydrated pentoxides are formed. The routinely applied techniques for dissolution of a Nb-Tarich sample is fusion with $\mathrm{KHSO}_{4}$ with further dissolution of the fused melt in 3\% (w/v) hot aqueous $\alpha$-hydroxy acid (tartaric, citric, etc.) solution. Being larger organic anions, citrates or tartrates retain the $\mathrm{Nb}(\mathrm{V})$ and $\mathrm{Ta}(\mathrm{V})$ in solution without allowing them to get hydrolyzed and precipitated. Fusion with highly corrosive NaF-KHF 2 flux, and further dissolution of the fused melt in sulphuric acid after fuming-off the fluoride (to prevent the attack on glass/quartz parts), resulted in a clear solution. Fusion with a mixture of $\mathrm{Na}_{2} \mathrm{HPO}_{4}-\mathrm{NaH}_{2} \mathrm{PO}_{4}$ flux and dissolution of the melt obtained in distilled water also resulted in a clear solution but with all the matrix elements in the solution to be analyzed. However, these methods were helpful in the rough estimation of the analytes in the sample so that a strategy for the separation of the elements desired could be designed.

Higher concentrations of uranium $(>10 \mu \mathrm{g} / \mathrm{mL})$ are known to interfere in the ICP-AES determination of many elements including REEs and Th. Results elsewhere (10) show that high concentrations of Nb-Ta also interfere in the most sensitive emission lines of elements such as Gd (364.749 nm), Dy (400.035 nm), Lu (261.542 nm), and La (333.749 $\mathrm{nm})$ through direct overlap of the emission lines of Mn and Ta. Table I depicts the extent of interference of uranium at $1 \mathrm{mg} / \mathrm{mL}$ concentration on the most sensitive analyte emission lines. The interference is severe on the $\operatorname{Pr}(422.293 \mathrm{~nm}), \mathrm{Sm}$ $(442.434 \mathrm{~nm}), \mathrm{Gd}(342.247 \mathrm{~nm})$, $\mathrm{Tb}(350.917 \mathrm{~nm}), \operatorname{Er}(349.910 \mathrm{~nm})$, and $\operatorname{Tm}(346.221 \mathrm{~nm})$ emission lines. Hence, for accurate and reliable determination of REEs in the presence of high concentrations of $\mathrm{Nb}, \mathrm{Ta}$, and $\mathrm{U}$, separation from the major matrix is mandatory.

During the course of this study, a few well-known separation methods including precipitation of analytes, hydroxides, and fluorides were tried. Hydroxide precipitation is not selective and precipitates the interfering matrix elements such as $\mathrm{Nb}, \mathrm{Ta}$, and $\mathrm{U}$ as well. Hence, it was not followed for quantitative separation of REEs in the presence of these matrices. Precipitation of the analytes as their fluorides and the formation of soluble fluorides of other concomitants was promising. But highly corrosive hydrofluoric acid in large quantities was necessary. During acid hydrolysis precipitation (8) of the major $\mathrm{Nb}$-Ta as their oxy-chlorides, the REEs were determined in the filtrate. This does not, however, remove uranium from the solution. Thus, an additional step to remove uranium from the REE solution is required and may lead to a loss of analytes with lower throughput of the samples containing uranium. Removal of uranium could either be performed by solvent extraction with tri-butyl phosphate (TBP) in kerosene (12) or employing the activated charcoal in fluoride medium (6-7). During the solid phase separation of REEs, Y, and Th as their fluorides on the activated carbon, it was found that residual uranium in the solid phase is high

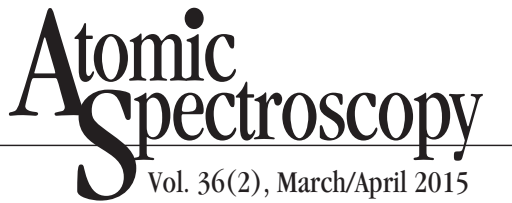

enough, about $20 \mu \mathrm{g} / \mathrm{mL}$, to interfere during emission measurements after single-step separation. The retention of uranium is thought to be due to occlusion of the element on the bulky precipitate of REEs formed with fluoride. Calcium also forms insoluble oxalates and contributes to the salt content if it is present in high amounts. Higher amounts of Ca content cools down the plasma and in turn reduces the emission intensities causing nonspectral interferences. To remove this, an additional hydroxide precipitation adding ammonium hydroxide could be performed (11). However, in the present study, as the solutions were diluted to a larger extent, the interference from calcium was not significant and did not warrant separation.

Trivalant REEs form oxalates with very low solubility in aqueous solution. It is a near specific method for quantitative separation of REEs, Y, and Th. REEs form oxalates with the general formula $\mathrm{L}_{2}\left(\mathrm{C}_{2} \mathrm{O}_{4}\right)_{3} \cdot n \mathrm{H}_{2} \mathrm{O}$. These oxalates are very fine crystalline precipitates and slowly convert to coarse crystalline ones. Under normal conditions, these oxalates crystallize with 10 molecules of water, except Yb and Lu. They form hydrates with lower water content. Since lighter rare earths (La-Gd) have higher ionic radii, their complexing ability is expected to be lower and lower recoveries, especially for $\mathrm{La}$ and $\mathrm{Ce}$, as reported in the literature (18).

LREEs (La-Gd) form sparingly soluble double sulphates, whereas for HREEs (Tb-Lu) double sulphates are soluble. Soluble salts of the mixture of REEs are usually treated with sodium or potassium sulphate. The cerium earths are precipitated as the sparingly soluble sulphates, $\mathrm{L}_{2}\left(\mathrm{SO}_{4}\right)_{3}$ where $\mathrm{L} n=\mathrm{La}-\mathrm{Gd}$ and the yttrium earths remain in solution as complexes of the $\mathrm{Na}_{3}\left(\mathrm{~L}^{*}\left(\mathrm{SO}_{3}\right)_{3}\right)$, where $\mathrm{L} n^{*}=\mathrm{Gd}-\mathrm{Lu}$. Hence, formation of double sulphates of the REEs is expected during dissolution 
of the cooled melt of the potassium bisulphate with the sample after fusion (18).

$$
\begin{aligned}
& \mathrm{K}^{+}+\mathrm{RE}^{3+}+2 \mathrm{SO}_{4}{ }^{2-}+\mathrm{x} \cdot \mathrm{H}_{2} \mathrm{O} \rightarrow \\
& \mathrm{KRE}\left(\mathrm{SO}_{4}\right)_{2} \cdot \mathrm{x} \mathrm{H}_{2} \mathrm{O}
\end{aligned}
$$

Co-precipitation of impurities with REE-oxalates is a fairly common occurrence. Thorium closely resembles the REEs and hence, oxalate of thorium is co-precipitated quantitatively with the REEs. Oxalates of $\mathrm{Zr}$ and $\mathrm{Hf}$ are also sparingly soluble and hence, could be co-precipitated. However, appreciable amounts could be prevented by using large excess of the precipitant, since $\mathrm{Zr}$ and $\mathrm{Hf}$ form complexes and remain in solution. Co-precipitation of REEs with sparingly soluble oxalates of the elements like $\mathrm{Ca}$, $\mathrm{Pb}$, and $\mathrm{U}(\mathrm{IV})$ is employed when the concentration of the REEs in the parent solution is low and isolation of the precipitate is difficult. The mechanism of co-precipitation is termed as adsorptive capture of REE-oxalate on Ca-oxalate. The selectivity of the co-precipitation could be improved by forced retention of impurities in the solution by complexation with EDTA (17). In the present study, no carrier was added during oxalate precipitation as the concentration of analytes was sufficient enough to precipitate independently.

\section{Optimization of Conditions}

Various factors like the flux to sample (F/S) ratio, $\mathrm{pH}$ of the resulting solution in aqueous media, amount of oxalic acid added, etc., affect the complete sample dissolution and further quantitative precipitation of the REE, Y, and Th oxalates.

A minimum of flux (hydrated $\mathrm{KHSO}_{4}$ ) to a sample ratio of 10:1 was required for obtaining a clear fused melt. Higher amounts of flux will increase the solids in the solution which adversely affect the nebulization efficiency.
The $\mathrm{pH}$ of the resulting aqueous solution after dissolution of the fused melt in $200 \mathrm{~mL}$ distilled water is $1 \leq \mathrm{pH} \leq 2$. Since the REEs, $\mathrm{Y}$, and Th are known to form oxalates at this $\mathrm{pH}$ and, moreover, quantitative recovery of the analytes was obtained, no further adjustment of $\mathrm{pH}$ was performed. However, on an increase of the $\mathrm{pH}$, the anionic complex of HREEs formed with oxalic acid tend to be more soluble and hence, loss of analyte is observed. Moreover, at a higher $\mathrm{pH}$, other concomitants such as iron, aluminium, etc., will precipitate and tend to increase the dissolved solids content of the solution. Ce(IV) does not form insoluble oxalates and is reduced by oxalate ions. The reduced Ce(III) forms insoluble oxalate with an excess of reagent. The solubility of the REE oxalates in aqueous acid solutions is extremely low, but the solubility in neutral and weakly alkaline solutions with an excess of the precipitant may be fairly high due to the formation of the complex species. Thus, ideally, the precipitation of oxalates is to be performed at low acidity (1-2 pH) and with an excess (2-5 fold) of precipitant, oxalic acid. Precipitation is done rapidly and at an elevated temperature to avoid the occlusion of the impurities during precipitation. At high $\mathrm{pH}$, the anionic complex of the analyte with oxalic acid is soluble and hence, analyte loss is encountered. In the literature (19), formation of three types of oxalates is reported: $\mathrm{L} n(\mathrm{Ox})^{+}, \mathrm{Ln}(\mathrm{Ox})_{2}{ }^{-}$, and $\mathrm{L} n(\mathrm{Ox})_{3}{ }^{3-}$.

At the right $\mathrm{pH}$, the concentration of oxalate ion is the governing condition for quantitative precipitation. The HREEs have pronounced tendencies towards forming soluble complexes. Depending on the amount of $\mathrm{Nb}, \mathrm{Ta}$, and $\mathrm{U}$, whose oxalates are soluble complexes and based on the concomitant elemental concentration whose oxalates are precipitated along with REEs, Y, and $\mathrm{Th}$, the oxalic acid requirement would vary (11). The concentration of oxalic acid was varied from $1-10 \%$ (above $12 \%$ oxalic acid forms a saturated solution). The analyte recovery was quantitative and the residual concentration of $\mathrm{U}$, $\mathrm{Nb}$, and $\mathrm{Ta}$ in the precipitated oxalates was less than the interfering limits (in most of the cases, these elements were below the detection limits of the instrument) at $\geq 4 \%(\mathrm{w} / \mathrm{v})$ oxalic acid itself. Hence, $4 \%$ (w/v) oxalic acid was fixed for further studies.

\section{Recovery of Analytes}

The analyte oxalate precipitate obtained was filtered and collected on a Whaman 542 filter paper which was treated with concentrated $\mathrm{HNO}_{3}$ alone for dissolution. Dong-Yong Chug et al. (19) have shown that the solubilities increase for a lanthanide ion with increasing acidity, and for a given acidity, the solubility decreases with an increase in atomic number from $\mathrm{La}$ to $\mathrm{Gd}$, and gradually increases from $\mathrm{Tb}$ to Lu. Moreover, since an excess amount of oxalic acid in the resulting solution is undesirable for ICPAES analysis, the solution was evaporated for oxidative removal of the oxalate ion with perchloric acid. The use of $\mathrm{HClO}_{4}$ is hazardous and hence, the precipitate was ignited at $650^{\circ} \mathrm{C}$ in a muffle furnace to remove the oxalate, resulting in the formation of carbonates or oxides depending upon the duration of ignition. Lanthanum forms an intermediate hydroxycarbonate. The La and Pr oxalates require higher temperature for decomposition, whereas the Th and Ce oxalates decompose at $360^{\circ} \mathrm{C}$. This was further evidenced from the effervescence seen on the addition of $6 \mathrm{~mL}$ of $6 \mathrm{M} \mathrm{HCl}$ acid right after the ignition. 


\section{Synergism Observed During Precipitation}

The lighter REEs (La-Gd) are quantitatively precipitated as oxalates in slightly acidic solutions; however, heavier elements (Tb-Lu) have the tendency to form soluble complexes and their precipitation becomes increasingly less quantitative (12). REEs form sparingly soluble double sulphates with $\mathrm{KHSO}_{4}$. The solubility decreases from La to $\mathrm{Lu}$, i.e., the double sulphates of LREEs are not recovered fully when precipitated, whereas the double sulphates of HREEs are moderately insoluble. Kul et al. (20) have shown that the rare earth double sulphates could be economically recovered from the sulphuric acid leach liquors by adding sodium sulphate at $50^{\circ} \mathrm{C}$ and have shown that the process could decontaminate the REE double sulphate from Th, $\mathrm{Fe}, \mathrm{Al}$, and $\mathrm{Mg}$. It was found that the recovery of $\mathrm{La}, \mathrm{Ce}, \mathrm{Eu}, \mathrm{Gd}$ oxalate was enhanced in the presence of $\mathrm{KHSO}_{4}$. From the data in Figure 1, it is evident that although the recovery of LREEs (La-Gd) was un-altered in the presence of
$\mathrm{KHSO}_{4}$, the recovery of HREEs ( $\mathrm{Lu}$, $\mathrm{Yb})$ was enhanced significantly.

\section{Improvement in Detection Limits}

Dissolution of a geological sample containing higher concentrations of uranium, niobium, and tantalum in mineral acids directly will lead to hydrolysis of $\mathrm{Nb}$ and $\mathrm{Ta}$. Hence, these samples were fused with a flux, and the resulting melt was dissolved in a solution containing complexing agents such as $\alpha$-hydroxy acids (citric acid, tartaric acid). Otherwise, the sample is directly fused with mixed phosphate fluxes, resulting in a clear solution containing all the matrix elements and the flux material. The detection limits for thorium and rare earth elements were determined before and after separation of uranium and are listed in Table I. Enhancement observed after separation of the analytes from the major matrix has also been tabulated. Improvement as high as $14.52 \%$ was observed for $\mathrm{Nd}$ and a minimum of $0.92 \%$ was observed for Eu.

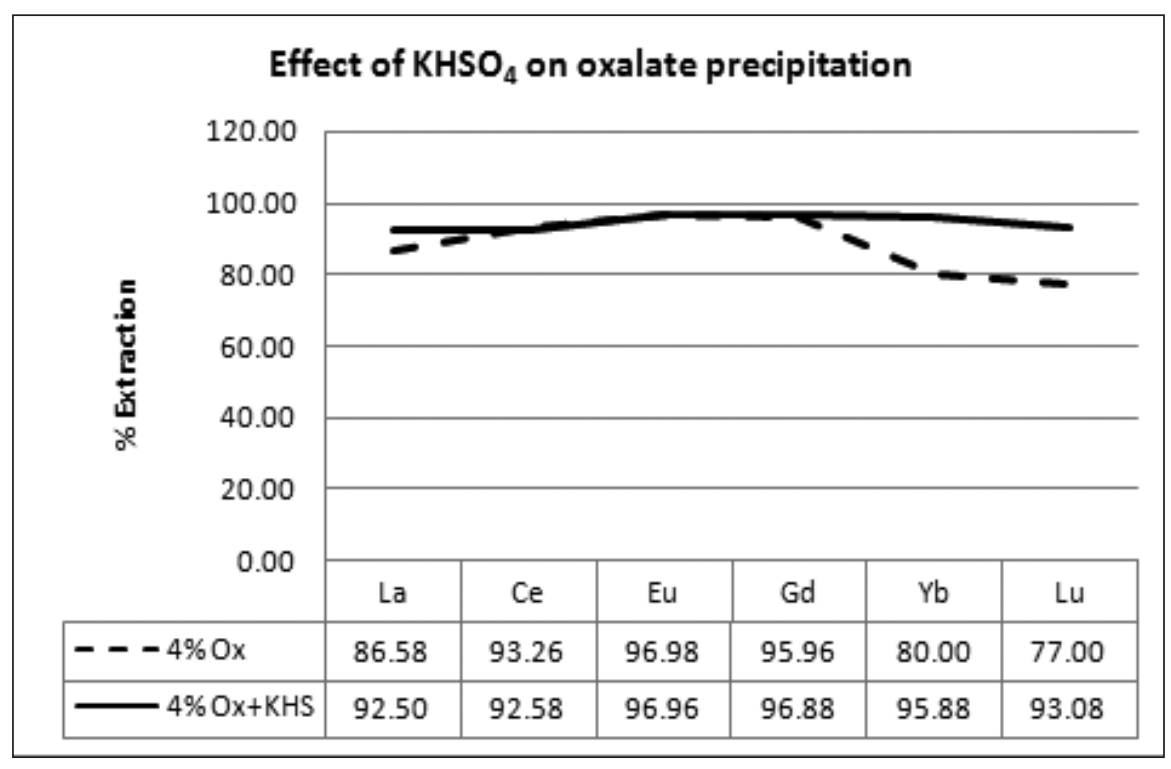

Fig. 1. Effect of $\mathrm{KHSO}_{4}$ (KHS) on the oxalate precipitation (Ox) of representative REEs at $p H=1$.

\section{Atomic Apectroscopy \\ $\bigcup$ Vol. 36(2), March/April 2015}

\section{Validation of the Method}

In order to validate the proposed method, a synthetic mixture containing selected REEs (La, Ce, Gd, Dy, and $\mathrm{Y}$ ) and Th as minor constituents and $\mathrm{U}, \mathrm{Nb}$, and $\mathrm{Ta}$ as major components was prepared from high purity oxides (Johnson Matthey, U.K.) of the corresponding elements (see Table II), fused with $\mathrm{KHSO}_{4}$, and oxalate precipitation was carried out as described above. The results show more than 95\% recovery of the selected REEs and $\mathrm{Th}$, whereas the residual of $\mathrm{U}$, $\mathrm{Nb}$, and $\mathrm{Ta}$ was less than $10 \mu \mathrm{g} / \mathrm{mL}$ in the aspirated solution. The recoveries obtained for La, Ce, Gd, Dy, Y, and Th were quantitative and reproducible with a RSD $\pm 1-3 \%$. In the absence of a suitable certified reference material, the proposed procedure was applied to standard reference material, IGS-33, Columbite (from Geological Sciences, British Geological Society, U.K.), doped with higher concentrations of uranium $(20 \mathrm{mg})$ containing trace level REEs, $\mathrm{Y}$, and Th in a niobium-rich matrix. The quantitative recovery of the analytes was obtained, and the results are listed in Table III. The results were compared with those obtained by acid hydrolysis precipitative separation of $\mathrm{Nb}$ and $\mathrm{Ta}$ and the analysis of the resulting filtrate (8), and were found to be in close agreement.

The proposed method was further validated by analyzing the samples with well-established separation methods such as acid hydrolysis of $\mathrm{Nb}$ and $\mathrm{Ta}$ (removal of the matrix), co-precipitation of REEfluorides with $\mathrm{Ca}$ as carrier, and solid phase extraction of REE-fluoride complex on activated charcoal leaving behind the soluble fluoride complexes of $\mathrm{U}, \mathrm{Nb}$, and Ta. However, these methods are tedious and cumbersome. Moreover, they involve use of corrosive HF acid and hence, are not eco-friendly. Separation involving many steps has the risk of analyte loss. 
TABLE II

Recovery Study of Selected REEs in the Presence of Major Amounts of $\mathrm{U}, \mathrm{Nb}$, and Ta by the Proposed Method in a Synthetic Mixture

\begin{tabular}{lrrcc}
\hline $\begin{array}{c}\text { Minor and Major } \\
\text { Oxides }\end{array}$ & $\begin{array}{c}\text { Added } \\
(\mu \mathrm{g})\end{array}$ & $\begin{array}{c}\text { Found } \\
(\mu \mathrm{g})\end{array}$ & $\begin{array}{c}\text { Recovery } \\
(\%)\end{array}$ & $\begin{array}{c}\text { RSD } \\
(\%)\end{array}$ \\
\hline $\mathrm{La}_{2} \mathrm{O}_{3}$ & 100 & 99 & 99.0 & 1.5 \\
$\mathrm{CeO}_{2}$ & 200 & 192 & 96.0 & 1.4 \\
$\mathrm{Gd}_{2} \mathrm{O}_{3}$ & 200 & 190 & 95.0 & 0.8 \\
$\mathrm{Dy}_{2} \mathrm{O}_{3}$ & 2000 & 1963 & 98.2 & 2.0 \\
$\mathrm{Y}_{2} \mathrm{O}_{3}$ & 20,000 & 19,543 & 97.7 & 0.9 \\
$\mathrm{ThO}_{2}$ & 200 & 188 & 94.0 & 1.1 \\
$\mathrm{Nb}_{2} \mathrm{O}_{5}$ & 80,000 & 400 & $<0.001$ & 1.0 \\
$\mathrm{Ta}_{2} \mathrm{O}_{5}$ & 20,000 & 400 & $<0.001$ & 1.0 \\
$\mathrm{U}_{3} \mathrm{O}_{8}$ & 20,000 & 300 & $<0.001$ & 1.1 \\
\hline
\end{tabular}

TABLE III

Comparison of Results Obtained for IGS-33

by the Proposed Procedure With Those Obtained by the Conventional Acid Hydrolysis Method

\begin{tabular}{lcccl}
\hline Elements & $\begin{array}{c}\text { Reported } \\
(\mu \mathrm{g} / \mathrm{g})\end{array}$ & $\begin{array}{c}\text { Acid } \\
\text { Hydrolysis } \\
(\mu \mathrm{g} / \mathrm{g})\end{array}$ & $\begin{array}{c}\text { Proposed } \\
\text { Procedure } \\
(\mu \mathrm{g} / \mathrm{g})\end{array}$ & $\begin{array}{c}\text { RSD } \\
(\%)\end{array}$ \\
\hline $\mathrm{La}$ & 134 & 138 & 134 & 1.7 \\
$\mathrm{Ce}$ & 426 & 519 & 467 & 1.6 \\
$\mathrm{Pr}$ & 42 & 39 & 40 & 1.4 \\
$\mathrm{Nd}$ & 166 & 181 & 169 & 3.4 \\
$\mathrm{Sm}$ & 61 & 70 & 63 & 1.2 \\
$\mathrm{Eu}$ & 1.6 & 1.5 & 1.6 & 2.1 \\
$\mathrm{Gd}$ & 85 & 92 & 89 & 0.8 \\
$\mathrm{~Tb}$ & 25 & 23 & 25 & 2.0 \\
$\mathrm{Dy}$ & 195 & 181 & 190 & 2.6 \\
$\mathrm{Ho}$ & 44 & 46 & 43 & 3.9 \\
$\mathrm{Er}$ & 199 & 196 & 192 & 3.3 \\
$\mathrm{Tm}$ & 50 & 50 & 46 & 2.6 \\
$\mathrm{Yb}$ & 448 & 428 & 432 & 1.8 \\
$\mathrm{Lu}$ & 72 & 76 & 76 & 2.7 \\
$\mathrm{Y}$ & 983 & 1012 & 1003 & 2.2 \\
\hline $\mathrm{Sm}$ & & & & \\
\hline
\end{tabular}

a Sample was decomposed by fusing with $\mathrm{Na}_{2} \mathrm{O}_{2}$ flux and the melt was dissolved in $\mathrm{HCl}$. The elements with valency III and above are precipitated as their hydroxides on heating with $\mathrm{NH}_{4} \mathrm{OH}$. The hydroxide precipitate is separated by filtration and boiled $\% \mathrm{HCl}$. The niobium/tantalum oxy-oxides or oxy-chlorides are precipitated on boiling. The REEs were measured in the filtrate (8).

\section{Application to Real Samples}

Table IV shows that the analytical results were obtained on four natural fergusonite/samarskite type samples received in our laboratory for elemental characterization. Out of these four samples, three were rich in HREEs which shows the trend of the fergusonite/samarskite type of samples reported in the literature (7). The fourth sample was analyzed as Ta-rich and found richer in LREEs. Figure 2 shows the chondrite normalized plots (9) for the four mineral samples and a standard reference material (IGS-33) analyzed.

\section{CONCLUSION}

The proposed procedure is effective in the precipitative separation of REEs, Y, and Th as their oxalates from $\mathrm{Nb}$-, Ta-, and U-rich materials. Since the analyte concentration was high enough, no carrier was added for precipitation. $\mathrm{KHSO}_{4}$ fusion and dissolution in aqueous media gave a $\mathrm{pH}$ of $\leq 2$ and hence, no further adjustment was necessary before addition of oxalic acid, and also was found acting as a synergistic reagent during the oxalate precipitation. Analyte solutions were decontaminated from $\mathrm{U}, \mathrm{Nb}$, and Ta almost completely. This method is rapid, quantitative, and environmentally friendly as it avoids any use of harmful reagents, including organic solvents. It could be utilized for routine determination of REEs, $\mathrm{Y}$, and $\mathrm{Th}$ in $\mathrm{Nb}$-, Ta-, and U-rich refractory minerals analyzed in large numbers from pegmatitic terrains during rare metal exploration.

\section{ACKNOWLEDGMENT}

The authors wish to thank Dr. A. Premadas, Chemistry Group, AMD, for his valuable suggestions during the preparation of this manuscript; Dr. G. Chakrapani, Head, Chemistry Group, AMD, for the encouragement to pursue research; 
TABLE IV

Results of Proposed Method for Real Refractory Geological Samples Rich in $\mathrm{U}, \mathbf{N b}$, and $\mathrm{Ta}$ Including Interfering Matrix Concentrations

\begin{tabular}{crrrr}
\hline Elements (\%) & SAM- 1 & SAM- & SAM-3 & SAM- 4 \\
\hline $\mathrm{La}$ & 0.011 & 0.031 & 0.019 & 0.805 \\
$\mathrm{Ce}$ & 0.067 & 0.062 & 0.074 & 1.627 \\
$\mathrm{Pr}$ & 0.003 & 0.038 & $<0.010$ & 0.189 \\
$\mathrm{Nd}$ & 0.271 & 0.305 & 0.048 & 0.861 \\
$\mathrm{Sm}$ & 0.455 & 0.501 & 0.054 & 0.186 \\
$\mathrm{Eu}$ & $<0.010$ & $<0.010$ & $<0.010$ & 0.010 \\
$\mathrm{Gd}$ & 1.334 & 1.384 & 0.397 & 0.170 \\
$\mathrm{~Tb}$ & 0.274 & 0.307 & 0.134 & 0.027 \\
$\mathrm{Dy}$ & 1.515 & 1.474 & 1.080 & 0.120 \\
$\mathrm{Ho}$ & 0.190 & 0.152 & 0.218 & 0.010 \\
$\mathrm{Er}$ & 0.357 & 0.248 & 0.689 & 0.011 \\
$\mathrm{Tm}$ & 0.051 & 0.041 & 0.115 & $<0.010$ \\
$\mathrm{Yb}$ & 0.169 & 0.103 & 0.719 & $<0.010$ \\
$\mathrm{Lu}$ & 0.001 & 0.000 & 0.074 & $<0.010$ \\
$\mathrm{Y}$ & 11.124 & 10.849 & 9.668 & 1.22 \\
$\mathrm{Th}$ & 0.540 & 0.680 & 0.290 & 0.63 \\
$\mathrm{Nb}_{2} \mathrm{O}_{5}$ & 35.780 & 38.699 & 21.229 & 10.34 \\
$\mathrm{Ta}_{2} \mathrm{O}_{5}$ & 12.526 & 8.064 & 4.020 & 40.946 \\
$\mathrm{U}_{3} \mathrm{O}_{8}$ & 5.460 & 9.000 & 3.400 & 0.68 \\
\hline
\end{tabular}

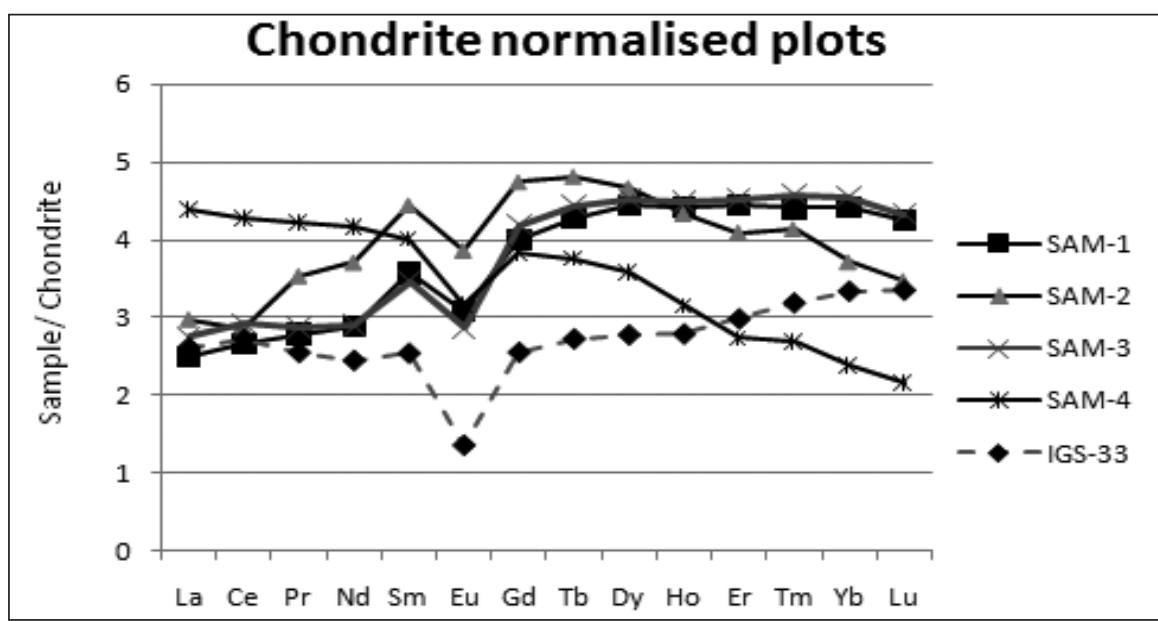

Fig. 2. Chondrite normalized plot obtained for samarskite type mineral samples and a Columbite reference material.

and Dr. A. K. Chathurvedi, Additional Director (R\&D), for the keen interest in the research and development work. The authors express their sincere thanks and gratitude to Shri. P.S. Parihar, Director, AMD, for his kind permission to publish the findings.

\section{Received October 18, 2014}

5. OM El. Hussaini and N.M. Rice, Hydrometall. 72(3), 259 (2004).

6. P. L. Mahanta, G. Chakrapani and R. Radhamani, At. Spectrosc. 31(1), 21 (2010).

7. Smeer Durani, M. Krishnakumar and K. Satyanarayana, J. Radioanal. Nucl. Chem. 294, 215 (2012).

8. K. Satyanarayana, At. Spectrosc. 17(2), 69 (1996).

9. P. Henderson (ed.), Rare Earth Element Geochemistry, Elsevier, The Netherlands (1984).

10. K. Satyanarayana, G. Srinivasan, R.K. Malhotra and B. N. Tickoo, Exploration and Research for Atomic Minerals, 2, 285 (1989).

11. A. Premadas, At. Spectrosc. 31(1), 14 (2012).

12. A. Premadas, V. V. Hanuman and V. N. Dwivedi, At. Spectrosc. 25(2), 70 (2004).

13. R. Radhamani, P. L. Mahanta, P. Murugesan and G. Chakrapani, J Radioanal. Nucl. Chem. 285, 287 (2010).

14. P. L. Mahanta, V. V. Hanuman, R. Radhamani and P. K. Srivastava, At. Spectrosc. 29(5), 172 (2008).

15. K. Satyanarayana and Smeer Durani, J. Radioanal. Nucl. Chem. 285, 659 (2010).

16. M. N. El-Hazek, T. E. Amer, M. G. Abu El-Azam, R. M. Issa, S. M. ElHady, Arabian J. of Chem. 5, 31 (2012).

17. M. Mark, M. Woyski and Ray E. Harris, Treatise on Analytical Chemistry, Part-II, Volume 8, Section A, Interscience Publishers, 10 (1963).

18. Appendix 20 Separation and gravimetric determination of REEs (Ref:D.I. Ryabchikov and V. A. Ryabukhin, Analytical Chemistry of Yttrium and Lanthanide Elements, Ann Arbor-Humphrey Publishers, London, U.K. (1970).

19. Don-Yong Chug, Eung-Ho Kim, E, H, Lee and J. J. Yoo, J. Ind. Eng. Chem. 4(4), 227 (1998).

20. M. Kul, Y. Topkaya and I. Karakaya, Hydrometall. 93, 129 (2008). 